\title{
Grand Challenge in Human/Animal Virology: Unseen, Smallest Replicative Entities Shape the Whole Globe
}

\author{
Akio Adachi ${ }^{1,2 *}$ \\ ${ }^{1}$ Department of Microbiology, Kansai Medical University, Osaka, Japan, ${ }^{2}$ Tokushima University, Tokushima, Japan
}

Keywords: human viruses, animal viruses, pathogenic viruses, virology, biology, multidisciplinary science

By far the most abundant species in nature is the virus that cannot replicate by itself. Viruses, parasitic entities, are found in virtually all unicellular and multicellular creatures. Viruses are everywhere. While smallest in size among all species, they can ingeniously replicate, persist, and survive in their individual hosts and/or host populations, and are transmittable among hosts. Viruses are sometimes inflicting or fatal for host species and are sometimes inter-species replicons. They keep interacting with their hosts in numerous different manners. Unseen viruses thus can reshuffle the whole world through accumulations of their subtle biological effects. In other words, viruses can shape the entire environment around us and are able to directly and/or indirectly influence us by their biologic activities. Virology is a multidisciplinary research field and, as an academic discipline of the biology, it extensively analyzes all aspects of viruses derived from every living species by scientific systems/methodologies currently available to us as exemplified and fully described in a series of Frontiers special issues designated "Research Topic" (RT) in the Virology section of Frontiers in Microbiology (Nomaguchi and Adachi, 2010, 2017; Miyazaki et al., 2012; Nomaguchi et al., 2012; Berkhout and Coombs, 2013; Sato et al., 2013; Adachi and Miura, 2014; Dutilh et al., 2017; Sanfaçon, 2017; Yamamoto et al., 2017). I wish to emphasize here again that virology is a branch of biological sciences studying the fundamental attributes of a wide variety of unique characteristic viruses. Virology concerns biological issues in a broad sense.

In the past decade, as many as of 1,500 articles approximately have been published and almost 80 RTs for specific subjects have been issued or are on the way in the Virology section. During this period, we have seen constant and vast increases both in virology-specific, in a narrow sense, articles, and in those giving more conceptual and general knowledge of the biology. Notably, the observed advances frequently have been accompanied by remarkable development of novel innovative technologies. In the next decade, concomitant with successful proceeding of the powerful and sharp analyzing systems and/or methods such as computational biology, structural biology, bioinformatics, multi-omics, next-generation sequencing, genome editing, single-cell methodology, and organoid technology (Bai et al., 2015; Angermueller et al., 2016; Chen et al., 2017; Dutta et al., 2017; Hasin et al., 2017; Adli, 2018; Artegiani and Clevers, 2018; Cheng, 2018; Ibrahim et al., 2018; Rossi et al., 2018; Sbalzarini and Greber, 2018; van Dijk et al., 2018; Pickar-Oliver and Gersbach, 2019), virology will certainly continue to contribute much to the progress in all areas of the basic biology from molecular and structural biology to environmental science. In addition, virology will surely represent one of major driving forces to solve a wide variety of practical issues, which are directly or indirectly related to the virus issue itself, i.e., nanotechnology, viral vectors, antiviral drugs, vaccines, gene therapy, interferon therapy, immune therapy, and so on (De Clercq, 2007; Guimarães et al., 2015; Szunerits et al., 2015; De Clercq and Li, 2016; Athanasopoulos et al., 2017; Grimm and Büning, 2017; Singh et al., 2017; Snell et al., 2017; Chambers et al., 2018; Colino et al., 2018; Kaufmann et al., 2018; Ono et al., 2018; Sulczewski et al., 2018; Vetter et al., 2018; Dionne, 2019; Graham et al., 2019). It is well-expected from our plentiful experience in the past 
decade that the Virology section, as an outstanding communication platform, plays a critical and central role in various activities of basic and applied sciences.

Human and animal virology investigates viruses that infect human and all species of animals. Upon replication, some viruses are damaging for their hosts to various degrees whereas others rather peacefully co-exist with the hosts. Among these viruses, those that cause serious infectious diseases in human and/or animals, are medically, socially, and economically of particular importance, as a matter of course for scientific significance. In fact, our Virology section has published numerous articles related to this kind of human and animal viruses and has edited relevant RTs in the past decade. On one hand, more general subjects covering various pathogenic viruses and related research areas have been targeted as well. Of socially important pathogenic viruses, some are solely tropic for humans, HIV-1 as an example (Hatziioannou et al., 2006, 2009; Kamada et al., 2006; Nomaguchi et al., 2008, 2013b), and some like human norovirus are known not to replicate in cultured cells (Duizer et al., 2004; HerbstKralovetz et al., 2013; Ettayebi et al., 2016; Murakami et al., 2020). Indeed, these viral properties hamper and limit our experimental strategies, and are representing major study projects to overcome in the virology. Alternative practical experimental systems, irrespective of being commonly useful and applicable to numbers of viruses or specifically to certain viruses, to circumvent the observed difficulties are definitely required. Expert researchers on the viruses have been making every effort to achieve the primary purposes (Kamada et al., 2006; Nomaguchi et al., 2011, 2013b; Soll et al., 2013; Hatziioannou et al., 2014; Ettayebi et al., 2016; Doi et al., 2018; Schmidt et al., 2019; Murakami et al., 2020). The trend described above is understandable and wellrecognized by published articles and RTs in the human and animal virus field in the Virology section. Most cited articles and most viewed $\mathrm{RT}$ in the human/animal virus field of the section (top 5, as of February 3, 2020) are as follows, respectively: articles, "Epidemiological aspects and world distribution of HTLV-1 infection" (Gessain and Cassar, 2012), "Pathology of asthma" (Kudo et al., 2013), "Challenges and opportunities in estimating viral genetic diversity from next-generation sequencing data" (Beerenwinkel et al., 2012), "ER stress, autophagy, and RNA viruses" (Jheng et al., 2014), and "Zika virus: the latest newcomer" (Saiz et al., 2016); RTs, "Highly mutable animal RNA viruses: adaptation and evolution" (Nomaguchi and Adachi, 2017), "Virus discovery by metagenomics: the (im)possibilities" (Dutilh et al., 2017), "Zika virus research" (Bueno-Marí et al., 2018), "Pathophysiology and epidemiology of virus-induced asthma" (Kimura and Ryo, 2014), and "Forefront studies on HTLV1 oncogenesis" (Mahieux and Watanabe, 2013). The results described above may indicate the research field in which our peers are mostly interested. Another point worth mentioning here is the emerging pathogenic viruses such as hemorrhagic Ebola virus and pneumonia-causing new coronavirus designated SARS-CoV-2. These viruses are becoming more and more important under today's world environment, as is the case for the influenza virus, a continuous global health threat, that potentially can induce an awful pandemic. It is more and more probable that humans may encounter emerging zoonotic viral pathogens and also re-emerging viruses through extensive inroads into untouched areas. We of course do not know much about the biology, including the ecology, origin, mutation, adaptation, etc., of these new viruses as yet. Once transmitted to humans, they readily replicate in and spread among human populations without effective immunity against them. Care should be taken not to be infected with the viruses at individual and population levels. Infected individuals must be treated properly. In this regard, we virologists always have to prepare the ground for sudden onsets of new emerging diseases. Routine collaborative research activities among basic researchers, clinical doctors, and relevant staffs of various expertise underpin the basis for swift responses against them. Valid anti-viral strategies can be generated by such well-organized medical teams.

Viruses can cause acute or chronic infections in human and animal hosts in many mechanistically different ways. While causative viruses for the former do not persist long in individual hosts in general, the latter viruses generate persistent infection and may give rise to latent infection. It is scientifically and practically important and of great interest to determine the underlying mechanisms. Elucidating biological and molecular bases for the conflict between viruses and their hosts is therefore one of major missions of current virology. Especially, for some pathogenic viruses that have incredibly lengthy interacting period with hosts, or that are prone to readily alter in nature, it is critically important to dynamically investigate their mutations, adaptation, and evolution. HIV-1, a representative virus for such category, readily mutates and adapts itself in the course of infection as experimentally revealed by a series of analytical studies (Nomaguchi et al., 2008, 2013a,c, 2014, 2016, 2017, 2018; Saito et al., 2011; Yokoyama et al., 2016; Doi et al., 2019). Here, following seven RTs in our Virology section are cited as examples of various cases for viral interactions with their hosts: "Codon usage and dinucleotide composition of virus genomes: from the virus-host interaction to the development of vaccines," "Host and pathogen mechanisms underpinning viral ecology and emerging infections," "Revealing HIV hiding places: identification and characterization of cellular and tissue reservoirs," "The interplay between innate immunity and herpesviruses," "HIV-1 genetic diversity," "Highly mutable animal RNA viruses: adaptation and evolution" (Nomaguchi and Adachi, 2017), and "The past and the future of human immunity under viral evolutionary pressure" (Hurst and Magiorkinis, 2019). As can be realized by the brief descriptions for the RTs and articles published in the RTs, there are indeed numerous distinct virus-host interactions to be noted. Lastly, regardless of their medical or economic effects on human society, all RNA and DNA viruses are equally valid targets for extensive scientific studies in today's virology. We aim to publish important articles resulting from those studies that significantly advance our understanding of the viruses and related issues in our Virology section.

The most noticeable topic in the field of human and animal virology in the next decade would depend upon what happens in the virological world around us. It could be a deadly virus that causes global infection, or, could be some discovery or invention that changes our concept. Attention should be paid to endogenized viral elements that affect the hosts in a biologically 
significant way. The relevant research field is rapidly growing as described recently in our journal (Staege and Emmer, 2018; Turnbull and Douville, 2018; Flynn and Moreau, 2019; Moelling and Broecker, 2019). As for the correct answer to the question above, it is of course unpredictable at the present time but the virological information and biological finding of the first magnitude that move the academic and public communities will surely determine the result. Based on enormous accumulations of scientific and statistical data of numerous kinds in various fields, together with orthodox and innovative analytical systems, it is quite expected that future virology can further deepen studies on virus populations and predictive science as well as those on a specific individual virus. From this point of view, I would like to enthusiastically encourage researchers outside the virology field, in addition to those who inside, to submit their representative works to our Virology section, if there is a little relevance. Virology is multidisciplinary in its marked and essential characteristic as stated above. Nevertheless, the bottommost role for current virology in the era of "Big Data" is to functionally/biologically characterize individual viruses for

\section{REFERENCES}

Adachi, A., and Miura, T. (2014). Animal model studies on viral infections. Front. Microbiol. 5:672. doi: 10.3389/fmicb.2014.00672

Adli, M. (2018). The CRISPR tool kit for genome editing and beyond. Nat. Commun. 9:1911. doi: 10.1038/s41467-018-04252-2

Angermueller, C., Pärnamaa, T., Parts, L., and Stegle, O. (2016). Deep learning for computational biology. Mol. Syst. Biol. 12:878. doi: 10.15252/msb.20156651

Artegiani, B., and Clevers, H. (2018). Use and application of 3D-organoid technology. Hum. Mol. Genet. 27, R99-R107. doi: 10.1093/hmg/ddy187

Athanasopoulos, T., Munye, M. M., and Yáñez-Muñoz, R. J. (2017). Nonintegrating gene therapy vectors. Hematol. Oncol. Clin. North Am. 31, 753-770. doi: 10.1016/j.hoc.2017.06.007

Bai, X. C., McMullan, G., and Scheres, S. H. W. (2015). How cryoEM is revolutionizing structural biology. Trends Biochem. Sci. 40, 49-57. doi: 10.1016/j.tibs.2014.10.005

Beerenwinkel, N., Günthard, H. F., Roth, V., and Metzner, K. J. (2012). Challenges and opportunities in estimating viral genetic diversity from next-generation sequencing data. Front. Microbiol. 3:329. doi: 10.3389/fmicb.2012.00329

Berkhout, B., and Coombs, K. M. (2013). Quantitative omics and its application to study virus-host interactions-a new frontier. Front. Microbiol. 4:31. doi: 10.3389/fmicb.2013.00031

Bueno-Marí, R., Saiz, J. C., Salomón, O. D., Villamil-Jiménez, L. C., Heukelbach, J., Alencar, C. H., et al. (2018). Editorial: Zika virus research. Front. Neurol. 9:168. doi: 10.3389/fneur.2018.00168

Chambers, A. C., Aksular, M., Graves, L. P., Irons, S. L., Possee, R. D., and King, L. A. (2018). Overview of the baculovirus expression system. Curr. Protoc. Protein Sci. 91, 5.4.1-5.4.6. doi: 10.1002/cpps.47

Chen, C., Huang, H., and Wu, C. (2017). Protein bioinformatics databases and resources. Methods Mol. Biol. 1558, 3-39. doi: 10.1007/978-1-4939-6783-4_1

Cheng, Y. (2018). Membrane protein structural biology in the era of single particle cryo-EM. Curr. Opin. Struct. Biol. 52, 58-63. doi: 10.1016/j.sbi.2018.08.008

Colino, C. I., Millán, C. G., and Lanao, J. M. (2018). Nanoparticles for signaling in biodiagnosis and treatment of infectious diseases. Int. J. Mol. Sci. 19:1627. doi: $10.3390 /$ ijms 19061627

De Clercq, E. (2007). The design of drugs for HIV and HCV. Nat. Rev. Drug Discov. 6, 1001-1018. doi: 10.1038/nrd2424

De Clercq, E., and Li, G. (2016). Approved antiviral drugs over the past 50 years. Clin. Microbiol. Rev. 29, 695-747. doi: 10.1128/CMR.00102-15

Dionne, B. (2019). Key principles of antiretroviral pharmacology. Infect. Dis. Clin. North Am. 33, 787-805. doi: 10.1016/j.idc.2019.05.006 the future by all available tools. By focusing on viruses, we can study and analyze living replicating creatures in all directions. We the Virology section of Frontiers in Microbiology most welcome the collaborative and integrative studies that impact and stimulate the whole world. Join us and share the fruits of virology.

\section{AUTHOR CONTRIBUTIONS}

$\mathrm{AA}$ is a sole contributor to this manuscript and approved its submission.

\section{ACKNOWLEDGMENTS}

I would like to thank Prof. Masako Nomaguchi (Tokushima University, Tokushima, Japan) for continuous hot/extensive discussions about Virology. I also appreciate Ms. Fumie Nishina (Kansai Medical University, Osaka, Japan) and Ms. Kazuko Yoshida (Tokushima University) for excellent editorial assistance.

Doi, N., Miura, T., Mori, H., Sakawaki, H., Koma, T., Adachi, A., et al. (2018). CXCR4- and CCR5-tropic HIV-1 clones are both tractable to grow in rhesus macaques. Front. Microbiol. 9:2510. doi: 10.3389/fmicb.2018.02510

Doi, N., Yokoyama, M., Koma, T., Kotani, O., Sato, H., Adachi, A., et al. (2019). Concomitant enhancement of HIV-1 replication potential and neutralizationresistance in concert with three adaptive mutations in Env V1/C2/C4 domains. Front. Microbiol. 10:2. doi: 10.3389/fmicb.2019.00002

Duizer, E., Schwab, K. J., Neill, F. H., Atmar, R. L., Koopmans, M. P., and Estes, M. K. (2004). Laboratory efforts to cultivate noroviruses. J. Gen. Virol. 85, 79-87. doi: 10.1099/vir.0.19478-0

Dutilh, B. E., Reyes, A., Hall, R. J., and Whiteson, K. L. (2017). Editorial: virus discovery by metagenomics: the (im)possibilities. Front. Microbiol. 8:1710. doi: $10.3389 /$ fmicb. 2017.01710

Dutta, D., Heo, I., and Clevers, H. (2017). Disease modeling in stem cell-derived 3D organoid systems. Trends Mol. Med. 23, 393-410. doi: 10.1016/j.molmed.2017.02.007

Ettayebi, K., Crawford, S. E., Murakami, K., Broughman, J. R., Karandikar, U., Tenge, V. R., et al. (2016). Replication of human noroviruses in stem cellderived human enteroids. Science 353, 1387-1393. doi: 10.1126/science.aaf5211

Flynn, P. J., and Moreau, C. S. (2019). Assessing the diversity of endogenous viruses throughout ant genomes. Front. Microbiol. 10:1139. doi: 10.3389/fmicb.2019.01139

Gessain, A., and Cassar, O. (2012). Epidemiological aspects and world distribution of HTLV-1 infection. Front. Microbiol. 3:388. doi: 10.3389/fmicb.2012.00388

Graham, B. S., Gilman, M. S. A., and McLellan, J. S. (2019). Structurebased vaccine antigen design. Annu. Rev. Med. 70, 91-104. doi: 10.1146/annurev-med-121217-094234

Grimm, D., and Büning, H. (2017). Small but increasingly mighty: latest advances in AAV vector research, design, and evolution. Hum. Gene Ther. 28, 1075-1086 doi: 10.1089 /hum.2017.172

Guimarães, L. E., Baker, B., Perricone, C., and Shoenfeld, Y. (2015). Vaccines, adjuvants and autoimmunity. Pharmacol. Res. 100, 190-209. doi: $10.1016 /$ j.phrs.2015.08.003

Hasin, Y., Seldin, M., and Lusis, A. (2017). Multi-omics approaches to disease. Genome Biol. 18:83. doi: 10.1186/s13059-017-1215-1

Hatziioannou, T., Ambrose, Z., Chung, N. P., Piatak, M. Jr., Yuan, F., Trubey, C. M., et al. (2009). A macaque model of HIV-1 infection. Proc. Natl. Acad. Sci. U.S.A. 106, 4425-4429. doi: 10.1073/pnas.0812587106

Hatziioannou, T., Del Prete, G. Q., Keele, B. F., Estes, J. D., McNatt, M. W., Bitzegeio, J., et al. (2014). HIV-1-induced AIDS in monkeys. Science 344, 1401-1405. doi: 10.1126/science. 1250761 
Hatziioannou, T., Princiotta, M., Piatak, M. Jr. Yuan, F., Zhang, F., Lifson, J. D., et al. (2006). Generation of simian-tropic HIV-1 by restriction factor evasion. Science 314:95. doi: 10.1126/science.1130994

Herbst-Kralovetz, M. M., Radtke, A. L., Lay, M. K., Hjelm, B. E., Bolick, A. N., Sarker, S. S., et al. (2013). Lack of norovirus replication and histo-blood group antigen expression in 3-dimensional intestinal epithelial cells. Emerg. Infect. Dis. 19, 431-438. doi: 10.3201/eid1903.121029

Hurst, T. P., and Magiorkinis, G. (2019). Editorial: the past and the future of human immunity under viral evolutionary pressure. Front. Immunol. 10:2340. doi: 10.3389 /fimmu.2019.02340

Ibrahim, B., McMahon, D. P., Hufsky, F., Beer, M., Deng, L., Mercier, P. L., et al. (2018). A new era of virus bioinformatics. Virus Res. 251, 86-90. doi: 10.1016/j.virusres.2018.05.009

Jheng, J. R., Ho, J. Y., and Horng, J. T. (2014). ER stress, autophagy, and RNA viruses. Front. Microbiol. 5:388. doi: 10.3389/fmicb.2014.00388

Kamada, K., Igarashi, T., Martin, M. A., Khamsri, B., Hatcho, K., Yamashita, T., et al. (2006). Generation of HIV-1 derivatives that productively infect macaque monkey lymphoid cells. Proc. Natl. Acad. Sci. U.S.A. 103, 16959-16964. doi: 10.1073/pnas.0608289103

Kaufmann, S. H. E., Dorhoi, A., Hotchkiss, R. S., and Bartenschlager, R. (2018). Host-directed therapies for bacterial and viral infections. Nat. Rev. Drug Discov. 17, 35-56. doi: 10.1038/nrd.2017.162

Kimura, H., and Ryo, A. (2014). Pathophysiology and epidemiology of virus-induced asthma. Front. Microbiol. 5:562. doi: 10.3389/fmicb.2014. 00562

Kudo, M., Ishigatsubo, Y., and Aoki, I. (2013). Pathology of asthma. Front. Microbiol. 4:263. doi: 10.3389/fmicb.2013.00263

Mahieux, R., and Watanabe, T. (2013). Forefront studies on HTLV-1 oncogenesis. Front. Microbiol. 4:156. doi: 10.3389/fmicb.2013.00156

Miyazaki, Y., Fujita, M., Nomaguchi, M., and Adachi, A. (2012). Structural biology for virus research. Front. Microbiol. 3:91. doi: 10.3389/fmicb.2012. 00091

Moelling, K., and Broecker, F. (2019). Viruses and evolution - viruses first? A personal perspective. Front. Microbiol. 10:523. doi: 10.3389/fmicb.2019. 00523

Murakami, K., Tengea, V. R., Karandikara, U. C., Lina, S. -C., Ramania, S., Ettayebia, K., et al. (2020). Bile acids and ceramide overcome the entry restriction for GII. 3 human norovirus replication in human intestinal enteroids. Proc. Natl. Acad. Sci. U.S.A. 117, 1700-1710. doi: $10.1073 /$ pnas.1910138117

Nomaguchi, M., and Adachi, A. (2010). Virology as biosystematics: towards understanding the viral infection biology. Front. Microbiol. 1:2. doi: $10.3389 /$ fmicb. 2010.00002

Nomaguchi, M., and Adachi, A. (2017). Editorial: highly mutable animal RNA viruses: adaptation and evolution. Front. Microbiol. 8:1785. doi: 10.3389/fmicb.2017.01785

Nomaguchi, M., Doi, N., Fujiwara, S., and Adachi, A. (2011). "Macaquetropic HIV-1 derivatives: a novel experimental approach to understand viral replication and evolution in vivo," in HIV-Host Interactions, ed T. L. Chang (Rijeka: IntechOpen), 325-348. doi: 10.5772/23624

Nomaguchi, M., Doi, N., Fujiwara, S., Saito, A., Akari, H., Nakayama, E. E., et al. (2013a). Systemic biological analysis of the mutations in two distinct HIV$1 \mathrm{mt}$ genomes occurred during replication in macaque cells. Microbes Infect. 15, 319-328. doi: 10.1016/j.micinf.2013.01.005

Nomaguchi, M., Doi, N., Kamada, K., and Adachi, A. (2008). Species barrier of HIV-1 and its jumping by virus engineering. Rev. Med. Virol. 18, 261-275. doi: 10.1002/rmv.576

Nomaguchi, M., Doi, N., Koma, T., and Adachi, A. (2018). HIV-1 mutates to adapt in fluxing environments. Microbes Infect. 20, 610-614. doi: 10.1016/j.micinf.2017.08.003

Nomaguchi, M., Doi, N., Sakai, Y., Ode, H., Iwatani, Y., Ueno, T., et al. (2016). Natural single-nucleotide variations in the HIV-1 genomic SA1prox region can alter viral replication ability by regulating Vif expression levels. J. Virol. 90, 4563-4578. doi: 10.1128/JVI.02939-15

Nomaguchi, M., Doi, N., Yoshida, T., Koma, T., Adachi, S., Ode, H., et al. (2017). Production of HIV-1 vif mRNA is modulated by natural nucleotide variations and SLSA1 RNA structure in SA1D2prox genomic region. Front. Microbiol. 8:2542. doi: $10.3389 /$ fmicb.2017.02542
Nomaguchi, M., Fujita, M., Miyazaki, Y., and Adachi, A. (2012). Viral tropism. Front. Microbiol. 3:281. doi: 10.3389/fmicb.2012.00281

Nomaguchi, M., Miyake, A., Doi, N., Fujiwara, S., Miyazaki, Y., TsunetsuguYokota, Y., et al. (2014). Natural single-nucleotide polymorphisms in the 3' region of the HIV-1 pol gene modulate viral replication ability. J. Virol. 88, 4145-4160. doi: 10.1128/JVI.01859-13

Nomaguchi, M., Yokoyama, M., Kono, K., Nakayama, E. E., Shioda, T., Doi, N., et al. (2013b). Generation of rhesus macaque-tropic HIV-1 clones that are resistant to major anti-HIV-1 restriction factors. J. Virol. 87, 11447-11461. doi: 10.1128/JVI.01549-13

Nomaguchi, M., Yokoyama, M., Kono, K., Nakayama, E. E., Shioda, T., Saito, A., et al. (2013c). Gag-CA Q110D mutation elicits TRIM5-independent enhancement of HIV-1mt replication in macaque cells. Microbes Infect. 15, 56-65. doi: 10.1016/j.micinf.2012.10.013

Ono, C., Okamoto, T., Abe, T., and Matsuura, Y. (2018). Baculovirus as a tool for gene delivery and gene therapy. Viruses 10:510. doi: 10.3390/v10 090510

Pickar-Oliver, A., and Gersbach, C. A. (2019). The next generation of CRISPRCas technologies and applications. Nat. Rev. Mol. Cell Biol. 20, 490-507. doi: 10.1038/s41580-019-0131-5

Rossi, G., Manfrin, A., and Lutolf, M. P. (2018). Progress and potential in organoid research. Nat. Rev. Genet. 19, 671-687. doi: 10.1038/s41576-018-0051-9

Saito, A., Nomaguchi, M., Iijima, S., Kuroishi, A., Yoshida, T., Lee, Y. J., et al. (2011). Improved capacity of a monkey-tropic HIV-1 derivative to replicate in cynomolgus monkeys with minimal modifications. Microbes Infect. 13, 58-64. doi: 10.1016/j.micinf.2010.10.001

Saiz, J. C., Vázquez-Calvo, Á., Blázquez, A. B., Merino-Ramos, T., EscribanoRomero, E., and Martín-Acebes, M. A. (2016). Zika virus: the latest newcomer. Front. Microbiol. 7:496. doi: 10.3389/fmicb.2016.00496

Sanfaçon, H. (2017). Grand challenge in plant virology: understanding the impact of plant viruses in model plants, in agricultural crops, and in complex ecosystems. Front. Microbiol. 8:860. doi: 10.3389/fmicb.2017. 00860

Sato, H., Yokoyama, M., and Toh, H. (2013). Genomics and computational science for virus research. Front. Microbiol. 4:42. doi: 10.3389/fmicb.2013. 00042

Sbalzarini, I. F., and Greber, U. F. (2018). How computational models enable mechanistic insights into virus infection. Methods Mol. Biol. 1836, 609-631. doi: 10.1007/978-1-4939-8678-1_30

Schmidt, F., Keele, B. F., Del Prete, G. Q., Voronin, D., Fennessey, C. M., Soll, S., et al. (2019). Derivation of simian tropic HIV-1 infectious clone reveals virus adaptation to a new host. Proc. Natl. Acad. Sci. U.S.A. 116, 10504-10509. doi: 10.1073/pnas.1818059116

Singh, L., Kruger, H. G., Maguire, G. E. M., Govender, T., and Parboosing, R. (2017). The role of nanotechnology in the treatment of viral infections. Ther. Adv. Infect. Dis. 4, 105-131. doi: 10.1177/2049936117713593

Snell, L. M., McGaha, T. L., and Brooks, D. G. (2017). Type I interferon in chronic virus infection and cancer. Trends Immunol. 38, 542-557. doi: 10.1016/j.it.2017.05.005

Soll, S. J., Wilson, S. J., Kutluay, S. B., Hatziioannou, T., and Bieniasz, P. D. (2013). Assisted evolution enables HIV-1 to overcome a high TRIM5 $\alpha-$ imposed genetic barrier to rhesus macaque tropism. PLoS Pathog. 9:e1003667. doi: 10.1371/journal.ppat.1003667

Staege, M. S., and Emmer, A. (2018). Editorial: endogenous viral elementslinks between autoimmunity and cancer? Front. Microbiol. 9:3171. doi: $10.3389 /$ fmicb. 2018.03171

Sulczewski, F. B., Liszbinski, R. B., Romão, P. R. T., and Rodrigues Junior, L. C. (2018). Nanoparticle vaccines against viral infections. Arch. Virol. 163, 2313-2325. doi: 10.1007/s00705-018-3856-0

Szunerits, S., Barras, A., Khanal, M., Pagneux, Q., and Boukherroub, R. (2015). Nanostructures for the inhibition of viral infections. Molecules 20, 14051-14081. doi: 10.3390/molecules200814051

Turnbull, M. G., and Douville, R. N. (2018). Related endogenous retrovirus-K elements harbor distinct protease active site motifs. Front. Microbiol. 9:1577. doi: 10.3389/fmicb.2018.01577

van Dijk, E. L., Jaszczyszyn, Y., Naquin, D., and Thermes, C. (2018). The third revolution in sequencing technology. Trends Genet. 34, 666-681. doi: 10.1016/j.tig.2018.05.008 
Vetter, V., Denizer, G., Friedland, L. R., Krishnan, J., and Shapiro, M. (2018). Understanding modern-day vaccines: what you need to know. Ann. Med. 50, 110-120. doi: 10.1080/07853890.2017.1407035

Yamamoto, T., Honda, A., Sato, T., and Ryo, A. (2017). Editorial: perspectives for the next generation of virus research: spearheading the use of innovative technologies and methodologies. Front. Microbiol. 8:758. doi: 10.3389/fmicb.2017.00758

Yokoyama, M., Nomaguchi, M., Doi, N., Kanda, T., Adachi, A., and Sato, H. (2016). In silico analysis of HIV-1 Env-gp120 reveals structural bases for viral adaptation in growth-restrictive cells. Front. Microbiol. 7:110. doi: $10.3389 /$ fmicb.2016.00110
Conflict of Interest: The author declares that the research was conducted in the absence of any commercial or financial relationships that could be construed as a potential conflict of interest.

Copyright (c) 2020 Adachi. This is an open-access article distributed under the terms of the Creative Commons Attribution License (CC BY). The use, distribution or reproduction in other forums is permitted, provided the original author(s) and the copyright owner(s) are credited and that the original publication in this journal is cited, in accordance with accepted academic practice. No use, distribution or reproduction is permitted which does not comply with these terms. 